\title{
Studies on Combustion Characteristics of Kerosene Alternative Fuels on a Special Vehicle Diesel Engine
}

\author{
Zhixin Sun ${ }^{1, a}$, Jialiang Wang ${ }^{2, b}$, Xinyong Qiao ${ }^{1, c}$ and Ning Ma ${ }^{1, d}$ \\ ${ }^{1}$ Department of Mechanical Engineering, Academy of Armored Force Engineering, \\ Beijing, China, 100072 \\ ${ }^{2}$ Equipment Engineering College, Engineering University of Chinese Armored Police Force, \\ Xi'an, China, 710086 \\ asunzhi-li@163.com, Corresponding author: bwjllongman@126.com, 'qxyaafe@sina.com, \\ dm18610465261@163.com
}

\begin{abstract}
Keywords: special vehicle; diesel engine; kerosene; emergency alternative fuels; combustion Abstract. Experimental studies to compare combustion characteristics of kerosene fuels and diesel fuel were performed in a single cylinder diesel engine respectively in order to find out if kerosene fuels could be used as alternative fuels in special vehicles in emergency. Three kinds of fuels such as $-10 \#$ diesel, aviation kerosene and lamp kerosene were tested. When fueled with lamp kerosene, the starting crank angles of Instantaneous Heat Release Rate curves are delayed; The peak values of Instantaneous Heat Release Rate decrease on rated condition, while increase on maximum torque condition due to the fast heat release rate of premixed combustion. The engine power loss is within $6.7 \%$ when fueled with kerosene fuels, and the Brake Specific Fuel Consumption decreases by $8.7 \%$.
\end{abstract}

\section{Introduction}

Special vehicles are used to carry out so many important works, such as military actions, engineering rescues and fire-fighting rescues. Considering the particularities of their working circumstances, they wouldn't accomplish their tasks for fuel shortage if their fuel supply chain, which consists of the fuel depots, fuel supply stations and pipelines are cut off. Therefore, how could we solve the fuel supply problem while the special vehicles have urgent tasks to accomplish fuel the special vehicle engines with alternative fuel that could be found easily without engine structure modification is a realistic measure. Kerosene is one of the best options.

Kerosene a middle distillate of petroleum based fuel. Generally, it can be classified as two types by purpose of use: aviation kerosene and lamp kerosene. In 2014, 4.84 billion tons of crude oil was mined, increased 3.8\% from previous year in China. And kerosene was 25.1 million tons, increased $16.4 \%$. In the ordinary life kerosene is used widely, and can be obtained easily [1]. Kerosene desulfurization, purification, straight-run crude fractions, secondary processing distillate, none thermal cracking component, it has higher calorific value, better cleaning ability and better low-temperature stability [2-3]. From 1990s, many abroad researchers have carried out studies on the performances and emissions on engines fueled with kerosene [4-8]. But no reports was retrieved about the special vehicle engines fueled with kerosene at home.

In the working process of diesel engine fueled with alternative fuels, the changes of fuel physical and chemical properties lead to the changes of fuel spraying characteristics, and directly affect the combustion efficiency, power output and economy of diesel engine [9]. Therefore, experimental studies on the kerosene fuel combustion characteristics on a single cylinder diesel engine bench were carried on in this paper, and the effects of kerosene fuel on engine power output and economy were analyzed. The results provide the experimental basis for the application of kerosene as special vehicles alternative fuels when emergency.

\section{Test Equipment and Scheme}

Test Equipment. This engine test was carried out on a single cylinder engine bench. Main parameters of the engine are shown in Table 1, and the bench setup is shown in Figure 1. The test 
equipment includes a Chengbang DL 55 electric dynamometer, Kistler 6125C cylinder pressure sensor, Kistler 2613B angle encoder, DEWE 801 combustion analyzer and Chengbang ET 2500 fuel consumption meter.

Table 1 Parameters of the engine

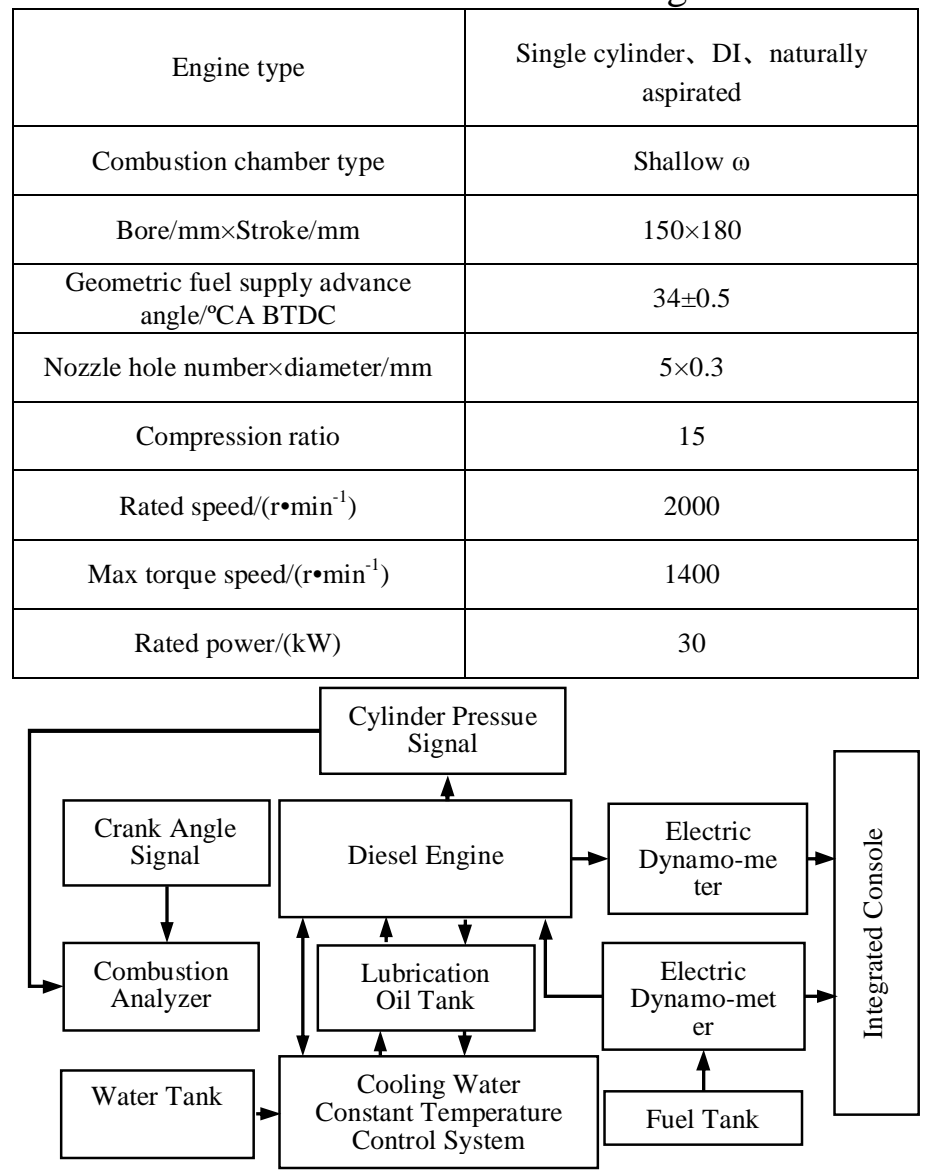

Figure 1. Diagram of the engine bench

Tested Fuels. Three kinds of fuels were tested: $-10^{\#}$ diesel, aviation kerosene and lamp kerosene. The main physical and chemical properties are shown in Table 2.

Table 2 Physical and chemical properties of the tested fuels

\begin{tabular}{|l|l|l|l|}
\hline Item & Diesel & $\begin{array}{l}\text { Aviation } \\
\text { kerosene }\end{array}$ & $\begin{array}{l}\text { Lamp } \\
\text { kerosene }\end{array}$ \\
\hline Density $\left(20^{\circ} \mathrm{C}\right) /\left(\mathrm{g}^{\circ} \mathrm{cm}^{-3}\right)$ & 834.0 & 785.4 & 794.0 \\
\hline Viscosity $\left(20^{\circ} \mathrm{C}\right) /(\mathrm{mm} 2 \bullet \mathrm{s}-1)$ & 4.611 & 1.506 & 1.826 \\
\hline Flash point $/{ }^{\circ} \mathrm{C}$ & 79.5 & 53.5 & 50.5 \\
\hline $10 \%$ recovery temperature $/{ }^{\circ} \mathrm{C}$ & 231.0 & 171.0 & 181.4 \\
\hline $50 \%$ recovery temperature $/{ }^{\circ} \mathrm{C}$ & 270.5 & 188.0 & 205.9 \\
\hline $90 \%$ recovery temperature $/{ }^{\circ} \mathrm{C}$ & 320.0 & 214.5 & 236.0 \\
\hline Cetane number & 50.8 & 53.5 & 49.1 \\
\hline Lower heat value $/(\mathrm{MJ} \cdot \mathrm{kg}-1)$ & 43.18 & 42.90 & 41.00 \\
\hline
\end{tabular}

As shown in table 2: compared with diesel fuel, aviation kerosene or lamp kerosene has significantly lower viscosity and density, better fluidity. But their flash point and distillation temperature are lower, which leads to worse safety. The cetane number of aviation kerosene is higher than that of diesel oil, while lamp kerosene is slightly lower. And the Lower Calorific Value of these two kinds of kerosene fuel are lower than that of diesel fuel. 


\section{Test Results and Analysis}

Analysis of Combustion Characteristics.Figure 2 presents the Instantaneous Heat Release Rate curves of engine fueled with diesel fuel and kerosene fuels.

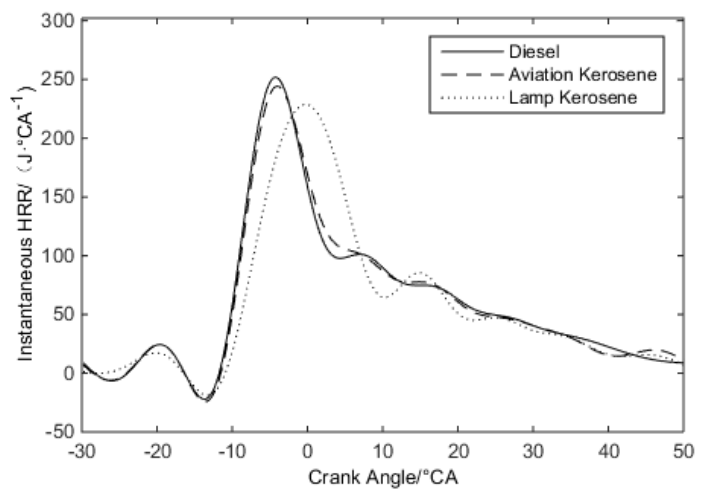

(1) Rated operating point

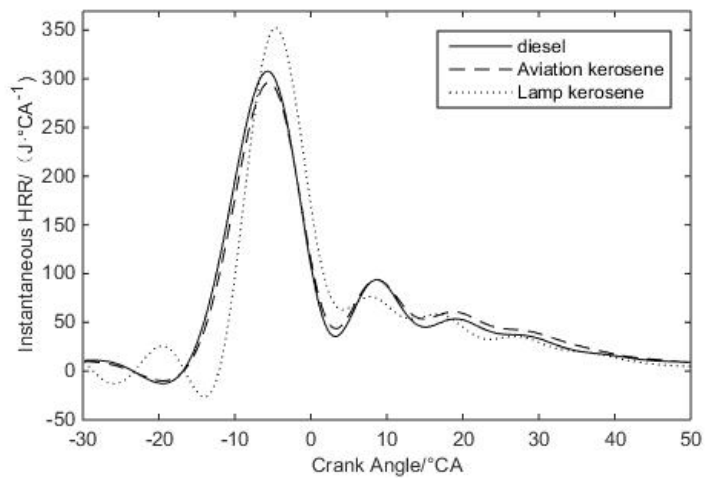

(2) Maximum torque operating point

Fig. 2 Comparison of instantaneous HRR when fueled with different fuels

As shown in Fig.2, at the rated operating point, while fueled with aviation kerosene and lamp kerosene the starting points of Instantaneous Heat Release Rate curves are $0.2^{\circ} \mathrm{CA}$ and $0.8^{\circ} \mathrm{CA}$ later than that fueled with diesel fuel.

The reason for this is that: on one hand, kerosene fuel has lower density, greater compressibility. The spreading velocity of the pressure wave in the kerosene fuel is slower. So the starting point of injection is later than that of the diesel [10]; On the other hand, from the spray characteristics test, we know that: compared with diesel, fuel spray of kerosene scatters greater, the atomization quality is better. These characteristics shorten the formation time of the premixed gas whose concentration is suitable for combustion. In addition, the cetane number of aviation kerosene is more than diesel, while lamp kerosene is lower. With the combined influences of the above three factors, the starting points of Instantaneous Heat Release Rate curves of the two kinds of kerosene fuels are slightly later than diesel fuel. In this working condition, the Instantaneous Heat Release Rate curves fueled with aviation kerosene and diesel fuel are almost the same, meanwhile when fueled with lamp kerosene the peak value of Instantaneous Heat Release Rate drops down, and the corresponding crank angle delays, and the premixed combustion rate slows down.

At the maximum torque operating point, the starting points of the engine fueled with aviation kerosene and lamp kerosene are later by $0.1{ }^{\circ} \mathrm{CA}$ and $4.7^{\circ} \mathrm{CA}$. This reason is that with the decrease of engine speed, the temperature in the cylinder drops down, and the effects of cetane number on the ignition are prominent. Due to the lower cetane number of lamp kerosene, the chemical preparation time of the pre-mixing process is longer, so the starting point is obviously delayed. At the same time, due to the longer combustion duration of kerosene, the pre-mixed combustible gas in the cylinder is 
increased, once the fuel is ignited, the Instantaneous Heat Release Rate becomes comparatively quick, and the peak value of the premixed heat release rate increased.

Impacts on Engine Performance. Figure 3 shows the power comparison of the engine fueled with the three kinds of fuel at either the rated operating point or the maximum torque operating point.

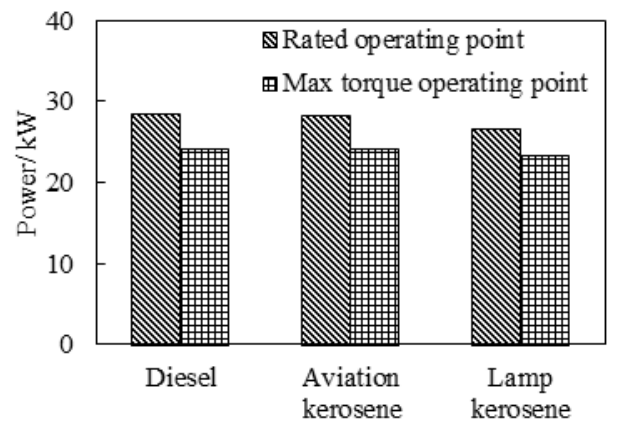

Fig. 3 Comparison of engine power when fueled with different fuels

It shows that when fueled with aviation kerosene, working at the rated operating point and the maximum torque point, the diesel engine powers are $28.1 \mathrm{~kW}$ and $24.0 \mathrm{~kW}$, about $1.5 \%$ lower than that of fueled with diesel. While fueled with lamp kerosene the engine powers are $26.6 \mathrm{~kW}$ and $23.3 \mathrm{~kW}$, about $6.7 \%$ and $3.4 \%$ lower than that of fueled with diesel.

The main reason is that: the lower density of lamp kerosene leads to smaller fuel injection amount in the same working condition. In addition, the calorific value of lamp kerosene becomes lower. These differences lead to the decrease of engine output power.

Figure 4 shows the Brake Specific Fuel Consumption of the engine fueled with three kinds of fuel at the rated operating point and the maximum torque operating point. It can be seen that Brake Specific Fuel Consumption of engine fueled with kerosene is less than that of diesel fuel. This is due to the smaller density of kerosene. In the same working condition the fuel amount by mass injected into the cylinder is smaller. Less heat is released and transmitted to engine power. For the aviation kerosene, the Brake Specific Fuel Consumption decreases by $5.8 \%$ and $8.7 \%$ at the rated operating point and the maximum torque operating point. Meanwhile for lamp kerosene, Brake Specific Fuel Consumption decreases by $2.1 \%$ and $7.2 \%$ at the same working condition.

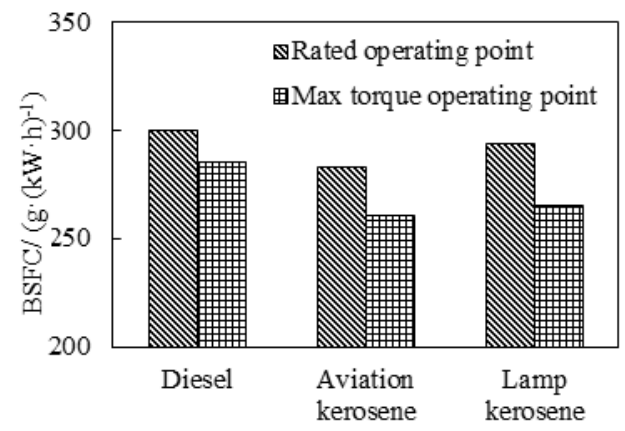

Fig. 4 Comparison of fuel consumption when fueled with different fuels

On the whole, the diesel engine power fueled with kerosene fuels decreases no more than $6.7 \%$, compared to diesel fuel. Brake Specific Fuel Consumption drops a little. From the impacts on engine performance, kerosene fuels can be used as alternative fuels for special vehicles in the case of diesel shortage in emergency.

\section{Conclusions}

(1) Compared with diesel fuel, the starting points of Instantaneous Heat Release Rate curves of lamp kerosene is later. At the maximum torque operating point, the engine has more premixed combustion, 
and release heat rapidly, so its maximum pressure rising rate increases $0.04 \mathrm{MPa} /{ }^{\circ} \mathrm{CA}$. And the peak values of the cylinder pressure decreases by $0.10 \mathrm{MPa}$. The exhaust gas temperature drops $30^{\circ} \mathrm{C}$.

(2) The engine power decreases no more than $6.7 \%$, and there is a small drop in the fuel consumption.

\section{Acknowledgements}

This work was financially supported by Academy of Armored Force Engineering (2014YY02).

\section{References}

[1] Wei Ying, Pan Feng, Wang Pengbo, etc. Pollutant Comparison between Aviation Kerosene Refining Processes and Corresponding Control Measures. Environmental Protection of Chemical Industry, Vol. 34(2014), p.276.

[2] Analysis of Chemical Constituents of Coal Liquefied Jet fuel distillate. Acta Petrolei Sinica (Petroleum Processing Section), Vol. 38(2010), p.264.

[3] Ostrovskii Y V, Zabortsev G M, Shpak A A, et al. Separation of the Tributyl Phosphate Kerosene Extraction Mixture Using Formic Acid. Radiochemistry, Vol. 45(2003), p.367.

[4] Andrews G E, Abdelhalim D M, Williams P T. Characterization of diesel particulate emission of two IDI diesel engines using diesel and kerosene fuels SAE Paper 961231, (1996).

[5] Bergstrand P. Effects on combustion by using kerosene or MK1 diesel. SAE Paper 2007-01-0002, (2007).

[6] Cracknell R F, Rickeard D J. Advanced combustion for low emissions and high efficiency part 2: impact of fuel properties on HCCI combustion. SAE Paper 2008-01-2404, (2008).

[7] Rose K D, Cracknell R F, Rickeard D J, et al. Impact of fuel properties on advanced combustion performance in a diesel bench engine and demonstrator vehicle. SAE Paper 2010-01-0334, (2010).

[8] Pischinger S, Rajamani V K, Jeihouni Y. Impact of fuel properties on the performance of a direct injection diesel engine under part homogeneous operating conditions. SAE Paper 2011-01-1358, (2011).

[9] Emekwuru N. Numerical characterization of two alternative-to-diesel fuels using a moments spray model.S AE Paper 2014-01-1422, (2014).

[10] An Qiaoqiao, Zhu Jianjun, Wang Jin, etc. Combustion and Emission Characteristics of Diesel Engine Fueled with Alternative Fuel Blends. Journal of Combustion Science and Technology, Vol. 20(2014), p.270. 